\title{
Movimento Roraimeira: contribuições interculturais e antropofágicas ao ensino de artes no estado de Roraima
}

Roraimeira movement: intercultural anthropophagic contributions and the arts education in the state Roraima

\author{
Ivete Souza da Silva* \\ Universidade Federal de Roraima \\ Clarisse Martins dos Santos** \\ Universidade Federal de Roraima
}

Resumo Este artigo é resultante de uma pesquisa de Iniciação Científica que teve como principal objetivo investigar as possíveis contribuições do processo antropofágico contido no Movimento Roraimeira para o ensino das artes no estado de Roraima, numa perspectiva intercultural de educação. Tal proposta surge da necessidade de se pensar uma educação voltada às particularidades do estado, tendo em vista a diversidade cultural presente em sua constituição, bem como, a precária qualificação profissional dos professores(as) atuantes no ensino de artes, os quais, em grande maioria não possuem formação na área. A pesquisa possui caráter bibliográfico onde foram analisadas as produções culturais do Movimento Roraimeira - 1988 a 2000 -, e discutidas com base em autores do campo da educação, do ensino de artes, da intercultura e da Antropofagia Cultural Brasileira.

PALAVRAS-CHAVE: Educação intercultural; Ensino de Artes; Movimento Roraimeira.

\begin{abstract}
This article is the result of a scientific initiation research that aimed to investigate the possible contributions of cannibalistic process contained in Roraimeira Movement for arts education in the state of Roraima, from an intercultural perspective of education. This proposal arises from the need to think about an education to the state's particularities, with a view to cultural diversity present in its constitution, as well as the poor professional qualifications of teachers (as) working in arts education, which, in large most have no training in the area. Research has bibliographical which analyzed the cultural productions of Roraimeira Movement - 1988 to 2000 - and discussed based on field of authors of education, arts education, intercultural and the Brazilian Cultural Antropofagia.
\end{abstract}

KEYWORDS: Intercultural education; Arts education; Roraimeira movement. 


\section{Introdução}

A pesquisa teve como principal objetivo analisar as contribuições dos ideais antropofágicos presentes no Movimento Cultural Roraimeira para pensar a educação e o ensino de artes visuais do estado de Roraima, a partir da perspectiva intercultural de educação. $\mathrm{O}$ estado de Roraima e sua capital Boa Vista, possuem uma grande pluralidade cultural decorrente da formação de seus habitantes, a qual percorre o espaço escolar, desafiando os docentes a lidarem com tal realidade. Considerando as particularidades locais e a necessidade da construção de uma prática educativa contextualizada, é que por meio desta pesquisa pretendeu-se contribuir teórica e epistemológicamente.

Para isso, esta investigação dividiu-se em três partes. A primeira parte foi voltada para o estudo sobre o Movimento Antropofágico. A poética antropofágica destaca a transformação dos produtos da cultura, mediante a incorporação do alheio, da diferença, em um processo de deglutição crítica, em que a junção de duas ou mais formas de culturas distintas, darão origem a uma terceira. A segunda parte teve foco no campo da Intercultura que debate entre as diversas concepções e propostas que enfrentam a questão da relação entre processos identitários socioculturais diferentes. Nesse campo se focaliza a possibilidade de respeitar as diferenças e de integrá-las em uma unidade que não as anule. Já na terceira parte concentramos a pesquisa no Movimento Cultural Roraimeira, iniciado na década de 1980, inspirado no Movimento Modernista e no Movimento Tropicalista, que teve por finalidade a construção cultural de uma identidade para o povo de Roraima, revestido nos elementos da cultura e da paisagem natural existentes no estado. Bem como, das transformações políticas que o estado estava vivendo. Para finalizar a pesquisa, analisamos algumas produções do Movimento Roraimeira através dos referenciais teóricos da Antropofagia Cultural Brasileira, da Intercultura e as relações entre esses campos com o ensino de artes aqui no Estado de Roraima.

Neste artigo, trazemos um recorte da pesquisa, optando por abordar, dentre as produções do Movimento Roraimeira a música "Roraimeira" de autoria de Zeca Preto, um dos precursores do movimento. A canção foi regulamentada como Hino Cultural do Estado pela Lei 1007/15, sancionada em 11 de Setembro de 2015.

\section{Um Brasil além da Linha do Equador: antropofagia na terra de Makunáima}

Atravessado pela Linha do Equador Roraima é o único estado brasileiro localizado no hemisfério norte, e sua capital Boa Vista é a mais distante do Distrito Federal. Mas, não é somente a distância do restante do Brasil, nem a dificuldade com que a população roraimense tem acesso as produções culturais e de consumo, que torna Roraima um estado particular. Junto com os estados do Amazonas, Rondônia, Para, Amapá, Mato Grosso, Tocantins, Acre e oeste do Maranhão, Roraima integra a Amazônia Legal, totalizando 59\% do território brasileiro e 65\% da Amazônia em seu conjunto (SOUZA, 2009), sendo 70\% do seu território reservas indígenas, que abrigam 8 (oito) etnias. Mesmo tendo grande parte do seu território destinado às comunidades indígenas o estado possui segundo dados do IBGE (2010), dos 450.479 
habitantes, apenas 55.922 indígenas, o restante são imigrantes das diversas regiões do país, principalmente da região norte e nordeste, e também estrangeiros vindos da Venezuela e Guiana Inglesa.

Tendo se tornado Estado Federado do Brasil em 1988 com a Constituição da República, Roraima vive ainda de forma intensa sua construção econômica/ social/cultural e política. Assim como o restante da Amazônia, a história de Roraima é marcada por práticas exploratórias que buscavam apropriar-se de suas riquezas naturais, provocando a imigração de brasileiros e estrangeiros e a morte de muitos indígenas que aqui viviam. Em busca de riqueza e de melhores condições econômicas muitas pessoas vieram, e ainda vêm para este canto desconhecido do Brasil. No entanto, grande parte das pessoas que migram para Roraima, em maioria para a capital Boa Vista, após algum tempo, retornam para os seus estados de origem, ou, seguem para outros estados, tornando a construção de uma identidade roraimense um entre-lugar (BHABHA, 2003) constante. Uma identidade que se inventa a partir do encontro e do convívio entre as várias culturas que por aqui passam, ou ficam. Roraima é como diria Canclini (2006), um local fronteiriço, não pela sua localização geográfica, mas, por abarcar em seu território elementos culturais de todo o Brasil e dos países vizinhos, que se relacionam sem uma definição exata, ou um processo de hibridação, sendo de lugar nenhum e de todo o lugar ao mesmo tempo. Essa diversidade cultural e as relações estabelecidas a partir delas, adentram o espaço escolar, desafiando os professores(as) a lidarem com tal realidade.

Os estudos sobre a contribuição dos pressupostos antropofágicos para a educação foram iniciados por Reigota (1999) em seu livro "A Floresta e a Escola", sendo mais tarde abordadas por Barcelos (2003 - atual), e Silva (2008, 2010, 2013, atual). A inspiração da noção de antropofagia vem da prática dos índios tupis que consistia em um ritual de alteridade no qual eles devoravam seus inimigos, mas não qualquer um, apenas os bravos guerreiros. Nesse ato antropofágico, não se come pelo apetite ou necessidade de nutrição, mas, para revigorar em si as qualidades assimiladas do inimigo. Ao devorar o outro, acreditava estar sugando a sua coragem e energia, numa ação de respeito e honra. O termo antropofagia foi resgatado como metáfora no Brasil do século XX, por Oswald de Andrade (1890 - 1954), sendo divulgado no Movimento Modernista na década de 1920. Marcado pela Semana de arte Moderna de 1922 este movimento contou com referências como Mario de Andrade, Anita Mafatti, Tarsila do Amaral, Raul Boop, Menotti del Picchia, Sérgio Milliet, Heitor Villa-Lobos, Víctor Brecheret, entre outros.

O conceito antropofágico trazido por Oswald, enquanto metáfora cultural, foi reformulado como resposta aos estímulos estéticos europeus. Este vanguarda denunciava o que entendia ser uma apropriação extrapolada e sem sentido da cultura estrangeira. Oswald propôs um antropofagismo literário que apropriava sem pudores de ideias e conceitos estrangeiros, defendendo que eles fossem devorados, assimilados por novos significados locais. A poética antropofágica destaca a transformação dos produtos da cultura, mediante a incorporação do alheio, da diferença, em um processo de deglutição crítica, em que a junção de duas ou mais formas de culturas distintas, darão origem a uma terceira. Não era ignorar as contribuições europeias o objetivo dos 
antropófagos, mas para a construção de uma identidade e arte nacional era preciso devorar o que o povo europeu, assim como os outros povos (africanos e ameríndios) que aqui viviam, nos proporcionava. Desta forma o Brasil nutre-se delas, transformando-as, criando outras formas de ver, observar o mundo num espaço cultural novo que logo seriam exportados como sendo a identidade nacional, cultura brasileira. No Manifesto Pau-Brasil (ANDRADE, 1924), o que se sugeria era a poesia de exportação contra a poesia de importação. A proposta primordial era a devoração da cultura importada e a sua reelaboração, resultando em um novo produto (DITTRICH, 2010). Em 1928 com o Manifesto Antropófago, Oswald de Andrade explica a importância de extrair de nossa cultura o que dela ainda queremos ou nos cabe manter, incorporando os elementos do que nos é estranho e novo, apresentado pelo estrangeiro.

Esses ideais antropofágicos foram difundidos e acabaram sendo a base de outros movimentos culturais e artísticos como o Movimento Tropicalista, considerado a segunda geração do Movimento Antropofágico. Outras produções artísticas, culturais e intelectuais foram construídas com base nos pressupostos antropofágicos nas diversas regiões do país em diferentes épocas, sendo o Movimento Roraimeira um exemplo desse exercício, segundo Eliakin Rufino (2009), um de seus criadores.

O Movimento Cultural Roraimeira acontece na década de 1980 quando o estado vive um período de intensa imigração de diferentes partes do país e, também, da Venezuela e Guiana Inglesa, recebendo principalmente imigrantes nordestinos que vêm trabalhar no garimpo de ouro, tendo estes a ilusão de melhorar significativamente as condições econômicas em que viviam, e, até mesmo de obter uma riqueza imediata. Esse momento foi marcado pela violência e a morte de muitos indígenas, pois grande parte dos garimpos eram localizados em terras indígenas. Diante deste cenário e aliado a situação de transformação do Território Federal de Roraima em Estado (1988), o Movimento Roraimeira, por meio de alguns artistas, dentre eles Zeca Preto, Neuber Uchoa e Eliakin Rufino, buscava em um primeiro momento, exaltar as riquezas naturais de Roraima e valorizar a forte contribuição dos povos indígenas para a formação cultural local. Segundo o pesquisador Oliveira et. al (2009), três elementos impulsionaram o movimento estimulando as produções entre 1988 e 2000, são eles: o ciclo garimpeiro da segunda metade da década de 1980; o crescimento demográfico acelerado; e a transformação do Território Federal de Roraima em Estado em 1988. Após o ano 2000 o grupo se separa centrando suas produções de forma individual, as quais traziam um olhar crítico para os problemas ambientais e culturais vividos no estado.

O "legado antropofágico" (ROCHA, 2011), ao ser transposto para a educação, e para o ensino de artes em particular, nos desafia a pensarmos a construção de uma prática pedagógica contextualizada, que vá ao encontro das necessidades locais. Propõe a criação de uma Pedagogia da Devoração (SILVA, 2008), construída a partir dos saberes e fazeres de cada pessoa envolvida no processo educativo. Nesse sentido, Fleuri e Souza (2003, p. 65), ao pensarem as questões culturais a partir de uma educação intercultural nos chamam a atenção para o fato de que, "a relação entre educação e cultura(s) não pode mais se limitar ao âmbito dos conteúdos culturais, ou do currículo escolar", pois, há que se considerarem as relações entre os diferentes sujeitos, e a forma como os mesmos a "agenciam". Esta necessidade vem ao encontro das proposições de 
Freire (1996) ao pensar a educação, quando o mesmo, em sua obra Pedagogia da Autonomia, sugere como um dos saberes indispensáveis à prática educativa o exercício de "saber escutar". Para o autor cada pessoa constrói sua leitura de mundo de acordo com sua cultura e a forma como a entende e a vivencia, saber escutar significa considerar tais saberes e fazeres para a construção da prática educativa. Freire (1996) sugere com isso, que o educador, parta da leitura de mundo do educando e com ele a supere construindo uma forma mais "crítica de inteligir o mundo".

Logo, para pensarmos e de fato construirmos, uma educação com bases interculturais e antropofágicas, que considere como matéria prima de sua criação o contexto e cultura local, é necessário escolhermos nossa comida. Então porque não devorar o Movimento Roraimeira? Porque não olhar o que ele tem a oferecer à educação de Roraima e ao ensino de artes?

\section{Movimento Roraimeira e o ensino de artes: alguns aponta- mentos}

O ensino contemporâneo de arte é marcado por uma mistura de tendências que influenciaram o ensino formal no Brasil. Dentre elas estão: a Pedagogia Tradicional; a Pedagogia Nova; a Pedagogia Tecnicista e as tendências Realistas-Progressistas. Conhecer essas tendências e suas propostas pedagógicas é de suma importância para que possamos, segundo Fusari e Ferraz (1993), entendermos nossas práticas educativas e nosso próprio processo de formação. Não é raro presenciarmos nas escolas práticas como: o desenho livre, ainda adotado por muitos professores para representar passeios e atividades realizadas na escola; e a reprodução de obras de arte que, talvez por uma tentativa de desenvolver uma abordagem triangular (BARBOSA, 1998), ganhou o nome de "releitura", mas em grande medida continua sendo uma cópia descontextualizada e despolitizada.

Tais considerações acerca do ensino das artes não são particularidades de um estado ou região brasileira, mas do contexto nacional da educação no país, que busca por meio de pesquisas e organizações como a FAEB (Federação de Arte/Educadores do Brasil), ABEM (Associação Brasileira de Educação Musical) e a ANPAP (Associação Nacional de Pesquisadores em Artes Plásticas), construir espaços de discussões sobre as problemáticas presentes no ensino das artes. No que se refere ao estado de Roraima em particular, este apresenta ainda problemas relativos a qualificação profissional, pois grande parte dos professores(as) que atuam no ensino de artes não possuem formação na área. São professores(as) formados em outras licenciaturas que, para atenderem as exigências da Lei de Diretrizes e Bases da Educação Nacional (9394/96), que em seu Art. 26. $\S 2^{\circ}$ determina o ensino de arte como componente obrigatório na educação básica, passam a atuar como professores(as) no ensino de artes.

O ensino da arte para ter sentido ao educando, assim como a educação de maneira geral, necessita estar articulado com os saberes que este leva consigo para dentro do espaço escolar. Daí a importância da construção de um espaço educativo propositivo onde o educando possa de fato entender-se como construtor do seu conhecimento. Ao apropriar-se do processo de construção do seu conhecimento o 
educando estará exercitando uma atitude questionadora, crítica, criativa e inventiva, ensaiando sua intervenção cidadã em outros espaços sociais, ultrapassando os muros da escola. A arte passa então a assumir o seu papel de ampliar fronteiras, como afirma Buoro (2001) resgatando a dimensão do humano como "ser social e cultural, leitor e interprete, criador e criatura”. Desta forma, a educação de maneira geral e o ensino das artes em particular, estarão contribuindo para a formação do educando enquanto sujeito crítico e reflexivo, capaz de ler o mundo em que vive e atuar na construção de alternativas para a resolução dos problemas do seu tempo. E que na construção dessas alternativas saiba considerar as diferentes leituras de mundo presentes em seu contexto.

Pensar o ensino de arte de Roraima a partir de elementos que lhe são próprios é de fundamental importância para o exercício de apropriação e criação do qual viemos falando. Os textos poéticos do movimento revelam os elementos do cotidiano, da cultura regional, da paisagem local, além do exotismo e a exuberância da natureza de Roraima. Vale ressaltar que a diversidade de identidade, característica do pluralismo cultural presente no Estado, também está contida nas canções. Percebemos tais afirmações na letra de uma das principais canções do movimento Roraimeira, a música do poeta Zeca Preto (1984) intitulada "Roraimeira":

Te achei na grande América do Sul

Quero atos que me falem só de ti

Em tua forma bela e selvagem

Entre os dedos o teu barro, o teu chão

E em tuas férteis terras enraizar

A semente do poeta Eliakin

nos seus versos inerentes ao amor

Aves ruflam num arribe musical

Os teus seios grandes serras

Grandes lagos são teus olhos

Tua boca dourada, Tepequém, Suapi

Terra do Caracaranã, do caju, seriguela

Do buriti, do caxiri, Bem-Querer

Dos arraiais do meu Hi-fi

Da morena bonita do aroma de patchuli

O teu importante rio chamado Branco

Sem preconceito em um negro ele aflui

És Alice nesse país tropical

De um cruzeiro norteando as estrelas

Norte forte, macuxi, roraimeira

Da coragem, raça, força garimpeira

Cunhantã roceira tão faceira

Diamante, ouro, amo-te poeira

(PRETO, 1984). 
Logo nos três primeiros versos, o poeta exalta a condição de migrante visto que ele é nativo do Pará, desta forma retrata seu encantamento ao encontrar Roraima na imensidão da América do Sul e seu interesse em conhecer os costumes e a história da região: "Te achei na grande América do Sul/Quero atos que me falem só de ti/Em tua forma bela e selvagem".

Já nos versos nono ao décimo primeiro, as belezas naturais do estado são enaltecidas como metáfora ao corpo humano, o poeta descreve a terra como se estivesse a descrever uma mulher, sugerindo sentimentos de apego a Roraima: "Os teus seios grandes serras/Grandes lagos são teus olhos/Tua boca dourada, Tepequém, Suapi”. Em seguida os frutos da região, caju, seriguela e o buriti, a bebida milenar da cultura dos povos indígenas presente no Estado, o caxiri, e lago e corredeira, Caracaranã e Bem-querer, são apresentados no poema. No décimo quinto verso, deparamos com um elemento da cultura do Pará: "Da morena bonita do aroma de patchuli". Patchuli é uma planta utilizada no artesanato paraense na confecção de chapéus, leques sendo empregada também na fabricação de aromas, do perfume de Patchuli. Através disso, o poeta aponta para a diversidade e a pluralidade presente na paisagem cultural de Roraima, usando como a marca identitária que remete a sua cidade natal. Outros elementos que reforçam essa ideia são encontrados no verso décimo sexto: "O teu importante rio chamado Branco/Sem preconceito de um negro ele aflui”. Podemos dizer que Zeca Preto fez nesse verso uma analogia a miscigenação, a abertura que o Estado concede as pessoas vindas de outras partes do Brasil, como os nordestinos, garimpeiros e povos dos países fronteiriços. $\mathrm{E}$ também nos versos vigésimo e vigésimo primeiro: "Norte forte, macuxi, Roraimeira/ Da coragem, raça, força garimpeira". Além de fazer referência a etnia indígena do Estado, o termo 'macuxi' é usado para designar as pessoas que nascem aqui, servindo como sinônimo de roraimense. Faz ainda analogia aos garimpeiros que chegaram ao Estado na década de 80.

Dessa forma nota-se a similaridade das proposições do movimento Modernista com o Movimento Roraimeira, pois as manifestações artísticas do Roraimeira exaltam a beleza estética das paisagens da Amazônia, mas também leva em consideração a pluralidade de culturas existente em Roraima. Tanto como tema, quanto como fonte de recursos expressivos, pressupõe a construção da identidade a partir da síntese da diversidade e da pluralidade presente em seu contexto. Essa diversidade e pluralidade cultural presente no Estado, percorre na educação, no espaço escolar. A intercultura é um campo de debate entre as diversas concepções e propostas que enfrentam a questão da relação entre processo identitários socioculturais diferentes (FLEURI, 2003). Nesse campo se focaliza a possibilidade de respeitar as diferenças e de integrá-las em uma unidade que não as anule. A educação nesse sentido passa a ser entendida como o processo construído pela relação entre diversos e diferentes sujeitos, propondo um ambiente criativo e formativo. Além de formar um espaço em que variados contextos culturais se interagem, esse campo se preocupa em construir uma disponibilidade para a leitura positiva da pluralidade social e cultural.

A partir das práticas educacionais, a educação intercultural sugere o desenvolvimento de estratégias que promovam a construção de identidades particulares e o reconhecimento das diferenças, ao mesmo tempo em que sustentam sua inter-rela- 
ção (FLEURI, 2003). Essa interação com uma cultura diferente contribui para que uma pessoa ou um grupo modifique sua perspectiva da realidade, pois o possibilita compreender ou adotar pontos de vista diferentes de interpretação da realidade ou de relação social. Dessa forma a antropofagia vem ao encontro deste pensamento a medida que propõe que não devemos ignorar o que já está instituído e sim devorá-lo, criando algo novo. Nesse sentido, um dos principais desafios à formação de professores é o de refletir suas práticas educativas, buscando desenvolver um novo olhar, uma nova postura, capaz de realcionar-se com as diferentes culturas que se entrelaçam no universo escolar, bem como de reinventar a escola, reconhecendo o que a especifica, identifica e distingue de outros espaços de socialização. Construir uma prática pedagógica contextualizada, que vá ao encontro das necessidades locais, como afirma Silva (2013). Aprender a lidar com a pluralidade de culturas, reconhecer os diferentes sujeitos socioculturais presentes em seu contexto, abrir espaços para a manifestação e valorização das diferenças.

Uma educação com bases interculturais parte do princípio da importância das relações entre as culturas e, não, na sua exploração como objeto de estudo. Segundo a perspectiva intercultural, o sujeito, os saberes e as experiências que ele constrói, a partir de suas relações, são o foco do processo educativo. Para tal, há que se recriar e reinventar algumas práticas pedagógicas, como, por exemplo, aquelas já cansadas e tristes, que teimam em tratar todas as pessoas e espaços como iguais, sem considerar suas particularidades e singularidades. Um bom lugar para se começar a mudança é por nós mesmos. Repensando nossas práticas, a importância delas para nosso estar no mundo e para as outras pessoas com quem e para quem, construímos e pensamos toda ação educativa.

O processo antropofágico que vem sendo apresentado, contribui para a viabilização desse espaço na medida em que propõe conhecer o outro, o estranho, o estrangeiro, olhando-o com olhos livres, para, assim, estabelecer relações com este outro e conhecê-lo/devorá-lo. A antropofagia oswaldiana, propõe um diálogo entre as diferentes culturas, sem imposição de verdades, hábitos ou costumes. A escola, nesse sentido, como muito bem sugere Azibeiro (2003, p. 87), poderia, buscar "compreender não só o que cada um quer dizer, mas também os contextos culturais a partir dos quais seus atos e suas palavras adquirem significados". Para tal ato sugerido pela autora, é preciso que nós, mulheres e homens, educadores e educadoras, estejamos dispostos a voltar nossos sentidos - olhos, ouvidos, tato, cheiro e paladar - para a realidade de cada contexto. É preciso que aprendamos e nos disponibilizemos a fazer a leitura das diferentes realidades, construídas nas relações entre as diferentes pessoas e sua cultura.

\section{Movimento Roraimeira: uma possibilidade antropofágica para pensar o ensino de artes em Roraima}

Os ideais antropofágicos e interculturais que foram apresentados nesse trabalho, possibilitam, a reflexão, o olhar, a compreensão e a valorização das diferenças culturais. Também sugere a valorização das relações interculturais pressupondo o diálogo entre essas diferentes culturas com os olhos livres, sem imposições. Propõem, a partir das práticas educacionais, o desenvolvimento de estratégias que promovam a 
construção de identidades particulares e o reconhecimento das diferenças, ao mesmo tempo em que sustentam sua inter-relação crítica e solidária, ou seja, não negar a si mesmo, mas também não negar o outro, o estrangeiro. A partir daí a importância do movimento Roraimeira para a educação do ensino das artes em Roraima, pois nas produções desse movimento podemos encontrar o contexto da cidade, dos costumes do povo que aqui vive.

A antropofagia, através dos pressupostos de devoração e da criação, propõe olhar com olhos livres as diferentes possibilidades do relacionar, do criar, do viver e do educar. Tais pressupostos auxiliam na busca de alternativas para lidar com os problemas e desafios de cada espaço educativo, possibilitando a construção de uma educação intercultural. Como diria Oiticica, "só existe o grande mundo da invenção" (2009), e nós brasileiros temos uma imensidade de fios soltos para tecer uma educação e uma pedagogia nossa. Característica. Basta para isso, lançarmos mão daquilo que temos a nossa disposição. Daí a importância de pensarmos as possíveis contribuições do Movimento Roraimeira para a educação de Roraima e para o ensino de artes em particular. A educação em Roraima necessita ser pensada a partir de Roraima e do povo roraimense. Parafraseando Oswald de Andrade (1972), diria que o Movimento Roraimeira, necessita de um exame cuidadoso, pois nele pode estar a chave para a construção de uma educação característica, que dialogue com seu contexto.

Marcio Souza (2010) ao se referir a história do Amazonas, estado que como Roraima compõe a Amazônia brasileira, afirma que esta é marcada pela aceitação de "códigos já devidamente mastigados e expelidos pela metrópole, numa constante copofagia cultural". O estado de Roraima, assim como o do Amazonas e outros estados da Amazônia brasileira é marcado por práticas copofagicas, que apenas importam modelos ditados por outras regiões do país, sem considerar sua diversidade étnica e cultural e as necessidades educativas, políticas, culturais e econômicas de seu povo. Chega de práticas copofagicas, é hora de assumirmos nossa antropofagia cultural e devorar seus princípios, pois como afirmou Oswald de Andrade,

[...] no fim da vida, nos seus últimos garranchos - os manuscritos estão na Unicamp -, escreveu uma carta e enviou para o Congresso dos Escritores, pedindo que dessem muita atenção para a antropofagia, pois a antropofagia era uma forma de civilização muito sofisticada, ainda não estudada, que merecia um exame mais cuidadoso, por parte de antropólogos, artistas e cientistas, porque era a chave para a compreensão do Brasil. Então ele dizia que para a vida não há salvação, não há messias, não, o que existe é o advento de um dia: a vida é devoração permanente. $\mathrm{E}$ essa alta sabedoria está na antropofagia. (CORRÊA, apud, COSTA, 2011, p. 74).

Oswald, assim como os demais antropófagos, sabia muito bem da importância da antropofagia, não só para a compreensão do Brasil, mas, também, para o curso de sua formação futura. Desejavam eles que nós brasileiros assumíssemos nossa criatividade e inventividade, sem negar o que somos e sem nos fecharmos ao estrangeiro. Que fossemos capazes de devorar o estrangeiro sem culpa ou sentimento de inferioridade, como sugeria Mario de Andrade (2008), para, assim, assumirmos nossa brasilidade e a partir dela construir nossas teorias, filosofias e, porque não dizer a nossa 
educação. No entanto, para o "exercício de uma impiedosa antropofagia", como afirma Roberto Gomes (1990), é necessário entendermos o que nos aconteceu. Desmontarmos nosso pensamento e postura colonizada que, ao longo da nossa história, fez com que acreditássemos que somente o que não nos pertencia era bom, e sentíssemos vergonha do nosso jeito brasileiro de ser, nossa cultura sempre em estado de hibridez.

Gomes ao discorrer sobre a construção de uma consciência brasileira, nos chama a atenção para o fato de que durante muito tempo vivemos a partir de modelos que não eram nossos. Vivemos querendo ser "não-brasileiro" (GOMES, 1990, p. 102). Primeiro desejamos ser europeus, depois desejamos ser norte-americamos. Estes são resquícios de um país que, segundo o autor, nasceu sem nenhuma pretensão de existir, pois as pessoas que para cá vieram pretendiam apenas acumular riquezas e retornar ao seu país de origem (GOMES, 1990). Fazendo dessas terras uma extensão das terras europeias, que produziria o que lá não era possível. Esse caminho acabou por gerar a negação de uma cultura que se reconhece como brasileira. Alias, vale lembrar que até o século XVIII "o termo brasileiro, como expressão e afirmação de uma nacionalidade, era praticamente inexistente” (MOOG. V, apud; GOMES, 1990, p. 101). Na educação não foi diferente. Ainda hoje buscamos nas referências estrangeiras receitas para os nossos problemas. No entanto o estrangeiro só pode ter algo a nos oferecer se for devorado antropofagicamente!

Ironicamente, ou tristemente, o estado de Roraima vive hoje o que o Brasil viveu em seu processo de colonização. Como um local de passagem e de busca de riquezas seus habitantes não se reconhecem como parte integrante deste. A identidade roraimense aos poucos vai sendo construída, e com ela e a partir dela, necessita-se buscar a edificação de uma educação comprometida com sua gente e problematizadora da sua realidade.

O antropófago, como bem afirma Antônio de Alcântara Machado ao apresentar a $1^{\text {a }}$ Dentição da Revista de Antropofagia, em Maio de 1928, "come o índio e come o civilizado: só ele fica lambendo os dedos. Pronto para comer os irmãos". Vamos então comer o Movimento Roraimeira e ver o que ele tem a oferecer para o ensino de artes no estado de Roraima. Devorar os seus princípios e com ele buscar uma educação "independente culturalmente de modelos estrangeiros" (ANDRADE, 1972). Que não tenha vergonha de ser o que é, e que esteja sempre pronta para comer os irmãos e lamber os dedos.

\section{Referências}

ANDRADE. O. Manifesto Poesia Pau-Brasil. Correio da Manhã. São Paulo, Março 1924. 1928. Manifesto Antropófago. Revista de Antropofagia, ANO I, N I. Piratininga, Maio,

Ponta de Lança. Rio de janeiro. Civilização Brasileira, 1972.

ANDRADE, M. Macunaíma: o herói sem nenhum caráter. Rio de Janeiro. Agir, 2008.

AZIBEIRO, N. E. Educação Intercultural e complexidade: desafios emergentes a partir das relações em comunidades populares. In: Educação Intercultural: mediações necessárias; FLEURI, R. M. (Org.). Rio de Janeiro. DP\&A, 2003. 
BARCELOS, V. H. L. Antropofagia Cultural e Educação Ambiental - contribuições à formação de professores(as). ANAIS da 28a. Reunião Anual da ANPED. Caxambu, 2003.

Antropofagia Cultural Brasileira e Educação Ambiental - contribuições à Formação de Professores(as). Projeto de Pós-Doutorado na Universidade Federal de Santa Catarina (UFSC), 2007a.

. Antropofagia e Epistemologia - por uma não-pedagogia na educação ambiental. Revista eletrônica do Mestrado em Educação Ambiental. PPGEA/FURG, Rio Grande - RS, 2010.

BARCELOS, V; SILVA. I. S. Saberes, sabores e devorações - para uma educação ambiental antropofágica e pós-moderna. In: CORREA. G.; PREVE. A. M. Ambientes da Ecologia: Perspectivas em política e educação. Santa Maria. UFSM, 2007.

BARBOSA, A. M. Tópicos Utópicos. Belo Horizonte. C/Arte, 1998.

BHABHA. H. K. O local da cultura. Belo Horizonte. Tradução: Mirian Ávila; Eliana Lourenço de Lima; Gláucia Renate Gonçalves. Editora UFMG, 2003.

BUORO, A. B. O olhar em construção: uma experiência de ensino e aprendizagem da arte na escola. São Paulo. Cortez, 2001.

BRASIL. Lei de Diretrizes e Bases da Educação Nacional. Lei 9394/96. Brasília, 1996.

Instituto Brasileiro de Geografia e Estatística. Disponível em: <www.censo2010.ibge. gov.br>. Acessado em: 22 fev. 2014.

CANCLINI, G. Consumidores e Cidadãos. Rio de Janeiro. UFRJ, 2006.

COSTA, L. V. P. Na boca do Estômago. Conversa com José Celso Martinez Corrêa. In: RUFFINELLI, J.; ROCHA, J. C. C. (Orgs). Antropofagia Hoje? Oswald de Andrade em cena. São Paulo: Prol Editora Gráfica, 2011.

DITTRICH, C. C. L. Banquete canibal e vanguarda: a viagem antropofágica. 2010. 107p. Dissertação (Mestrado em Literatura)- Universidade Federal de Santa Catarina, Florianópolis, 2010.

FREIRE, P. Pedagogia do Oprimido. Rio de Janeiro. Paz e Terra, 1983.

Pedagogia da Autonomia. São Paulo. Paz e Terra, 1996.

Professora sim tia não: cartas a quem ousa ensinar. São Paulo. OLHOd'agua, 2001b.

FLEURI, R. M. Educação Intercultural: mediações necessárias. In: Educação Intercultural: mediações necessárias; FLEURI, R.M. (Org). Rio de Janeiro. DP\&A, 2003.

FLEURI, R.M E SOUZA, M. I. P. de. Entre limites e limiares de culturas: educação na perspectiva intercultural. In: Educação Intercultural: mediações necessárias; FLEURI, R.M. (Org). Rio de Janeiro. DP\&A, 2003.

FUSARI, M. F. R.; FERRAZ, M. H. C. T. Arte na Educação Escolar. São Paulo. Cortez, 1993. GOMES, R. Crítica da Razão Tupiniquim. São Paulo. FTD, 1990.

OITICICA, H. Encontros. Rio de Janeiro. Beco do Azougue Editorial, 2009.

OLIVEIRA. R. S. et al. Identidade e Poesia musicada: panorama do Movimento Roaraimeira a partir da cidade de Boa Vista como fonte de inspiração. In: Revista Acta Geográfica, Ano III, No 6, Jul/Dez 2009. p. 217-37.

PRETO, Z. Roraimeira (1984). In. OLIVEIRA, R. S.; WANKLER, C. M.; SOUZA, C. M. Identidade e Poesia Musicada: 97 Panorama do Movimento Roraimeira a partir da cidade de 
Boa Vista como uma das Fontes de Inspiração. Revista Acta Geográfica, ano III, n6, jul./dez. de 2009. p. 27-37.

REVISTA RAIZ. Cultura do Brasil. 7 de Dezembro de 2006. Disponível em: <http://revistaraiz.uol.com.br/portal/index.php?option=com_content\&task=view\&id=241\&Itemid=180>. Acessado em: 26 fev. 2014.

REIGOTA. M. A Floresta e a Escola: por uma educação ambiental pós-moderna. São Paulo - SP. Cortez, 1999.

ROCHA, C. Uma Teoria da Exportação? Ou: Antropofagia como visão de mundo”. In: RUFFINELLI, J.; ROCHA, J. C. C. (Orgs). Antropofagia Hoje? Oswald de Andrade em cena. São Paulo: Prol Editora Gráfica, 2011.

RUFINO, E. In: OLIVEIRA, R. S.; WANKLER, C. M.; SOUZA, C.M. Identidade e Poesia Musicada: 97 Panorama do Movimento Roraimeira a partir da cidade de Boa Vista como uma das Fontes de Inspiração. Revista Acta Geográfica, ano III, n 6, jul./dez. de 2009. p. 27-37.

SILVA, I. S. As Contribuições Ecologistas da Antropofagia Cultural Brasileira para uma Pedagogia da "Devoração". Trabalho de Conclusão de Curso. Universidade Federal de Santa Maria, Centro de Educação (UFSM-CE), 2008.

. Educação Ambiental, Intercultura e Antropofagia Cultural Brasileira: contribuições para a Formação de Professores(as). \{Dissertação de Mestrado]. Programa de Pós-Graduação em Educação, Universidade Federal de Santa Maria (PPGE/UFSM), 2010.

. Antropofagia Cultural Brasileira e as práticas inventivas de Hélio Oiticica, Paulo Freire e Augusto Boal: contribuições ecologistas e interculturais para a Formação de Professores(as). Tese de Doutorado em Educação. Programa de Pós-Graduação em Educação, Universidade Federal de Santa Maria (PPGE/UFSM), 2013.

SOUZA, M. História da Amazônia. Manaus. Valer, 2009.

. A expressão Amazonense. Manaus. Valer, 3a Ed. 2010.

* Professora doutora da Universidade Federal de Roraima, Boa Vista, Roraima, Brasil.

** Graduanda em Artes Visuais pela Universidade Federal de Roraima, Boa Vista, Roraima, Brasil.

\section{Correspondência}

Ivete Souza da Silva - Curso de Artes Visuais/Universidade Federal de Roraima. Campus Paricarana: Av. Cap. Ene Garcez, no 2413. Bairro Aeroporto. Bloco 1. Sala 130.

E-mail: ivete.silva@ufrr.br-clarissemartins@live.com

Recebido em 01 de novembro de 2015

Aprovado em 12 de fevereiro de 2016 